\title{
A prototype system for observing the Atlantic Meridional Overturning Circulation - scientific basis, measurement and risk mitigation strategies, and first results.
}

\section{Torsten Kanzow ${ }^{1}$, Joël J.-M. Hirschi ${ }^{1}$, Christopher Meinen ${ }^{2}$, Darren Rayner ${ }^{1}$, Stuart A.} Cunningham $^{1}$, Jochem Marotzke ${ }^{3}$, William E. Johns ${ }^{4}$, Harry L. Bryden ${ }^{1}$, Lisa M. Beal ${ }^{4}$, Molly O. Baringer $^{2}$

${ }^{1}$ National Oceanography Centre, Empress Dock, Southampton, SO14 3ZH, U.K.

${ }^{2}$ NOAA Atlantic Oceanographic and Meteorological Laboratory, 4301 Rickenbacker Causeway, Miami, FL 33149, U.S.A.

${ }^{3}$ Max-Planck-Institut für Meteorologie, Bundesstraße 53, 20146 Hamburg, Germany

${ }^{4}$ Rosenstiel School of Marine and Atmospheric Science, 4600 Rickenbacker Causeway, FL 33149, U.S.A.

corresponding author:

Torsten Kanzow, Tel. : +44 23 80596044, Email: tok@noc.soton.ac.uk

Date: 28-01-2008, revised manuscript for Journal of Operational Oceanography

\begin{abstract}
The Atlantic Meridional Overturning Circulation (MOC) carries up to one quarter of the global northward heat transport in the Subtropical North Atlantic. A system monitoring the strength of the MOC volume transport has been operating since April 2004. The core of this system is an array of moored sensors measuring density, bottom pressure and ocean currents. A strategy to mitigate risks of possible partial failures of the array is presented, relying on backup and complementary measurements. We decompose the MOC into 5 components, making use of the continuous moored observations, and of cable measurements across the Straits of Florida, and wind stress data . The components compensate for each other, indicating that the system is working reliably. The yearlong average strength of the MOC is $18.7 \pm 5.6 \mathrm{~Sv}$, with wind-driven and density-inferred transports contributing equally to the variability. Numerical simulations suggest that the surprisingly fast density changes at the western boundary are partially linked to westward propagating planetary waves.
\end{abstract}




\section{Introduction}

The Atlantic meridional overturning circulation (MOC) carries warm, near-surface water northward towards high-latitudes and in turn transports cold, dense waters southward at depth. ${ }^{1}$ In the North Atlantic, the warm branch is part of the Gulf Stream / North Atlantic Current system (Fig. 1). Entering the Subarctic seas the waters have become continuously denser due to gradual heat loss to the atmosphere. Cold deep water is then formed by deep-ocean convection in the Greenland and Labrador Seas. This North Atlantic Deep Water (NADW) returns southward, mainly in a deep western boundary current (DWBC) below $1000 \mathrm{~m}$ depth along the coast line of the Americas. ${ }^{2}$ The MOC plays an important role in the Earth's climate system as it transports about $1.3 \mathrm{PW}$ heat northward in the subtropical North Atlantic ${ }^{3}$, which is about $25 \%$ of the total (i.e. atmospheric and oceanic) maximum heat transport. The MOC related heat transport moderates the Northeast Atlantic climate significantly. ${ }^{4}$

Palaeo-climate reconstructions reveal that the strength of the MOC and the related heat transport changed dramatically throughout the Earth's history - on time scales as short as a decade..$^{5}$ Numerical simulations show that a shutdown of the MOC would leave moderate and high latitude North Atlantic regions including Western Europe significantly cooler ${ }^{6}$ - with maximum cooling of up to $8{ }^{\circ} \mathrm{C}$ near Greenland. A possible mechanism leading to a significant reduction of the strength of the MOC is the increase in greenhouse gas forcing, as the induced warming would strengthen the vertical density stratification of the water column and thus suppress NADW formation. An intercomparison of 11 coupled ocean-atmosphere climate model simulations under greenhouse gas forcing showed that the MOC might decrease by 10 to $50 \%$ over the next 140 years. $^{7}$

The strength and the vertical structure of the MOC have only been measured very sporadically in the past ${ }^{8,9,10}$. Even though technologies for continuous horizontally integrating transport measurements have been around since the $1980 \mathrm{~s}^{11,12,13}$, continuous MOC time series spanning several years or decades and resolving intra-seasonal variability do not exist. Therefore, basic 
features of the MOC are unknown, such as the variability on intra-seasonal to decadal time scales ${ }^{14}$, the response to local wind stress forcing ${ }^{15}$ or the relative importance of wind-stress and buoyancy forcing on sub-seasonal to decadal time scales. ${ }^{16}$

Whether the MOC is already on the decline, is currently under debate. Based on 5 hydrographic sections at $25 \mathrm{~N}$ in the Atlantic it was concluded that there had been a reduction in the strength of the MOC from $22.9 \mathrm{~Sv}^{\mathrm{A}}$ to $14.8 \mathrm{~Sv}$ (or roughly by $30 \%$ ) between 1957 and $2004 .{ }^{10}$ At mid-latitudes a decline of the MOC from 19.2 to $16.9 \mathrm{~Sv}$ between 1997 and 2002 based on two hydrographic sections has been reported. ${ }^{17}$ Using a combination of direct and indirect transport measurement techniques a gradual decrease in the amount of cold dense overflow of deep waters through the Faroe Bank Channel (feeding the NADW) amounting to $1-2 \mathrm{~Sv}$ has been found since $1970 .{ }^{18}$ On the other hand, the DWBC in the Labrador Sea seems to have increased by roughly 4 Sv or $15 \%$ when comparing the 1996-1999 and 2000-2005 periods ${ }^{19}$, whereas no significant changes in the strength of the DWBC off Grand Banks (43 N) have been found comparing 1993-95 and 1999-2005 periods. ${ }^{20}$ Also, changes in strength of he DWBC do not necessarily reflect changes in the total MOC as offshore re-circulations may vary substantially in time, too. ${ }^{21,22}$ Thus, the historic observations either lack sufficient temporal resolution to derive the low-frequency evolution of MOC or they only capture a certain contribution of the MOC, which may not be representative for the whole.

A pilot system to continuously observe the zonally integrated meridional flow as a function of depth across $26.5 \mathrm{~N}$ (and thus the MOC) has been operating since April 2004. The project is funded from 2004 to 2008 in the framework of the Rapid Climate Change (RAPID) thematic programme of the UK Natural Environment Research Council (NERC), the US National Science Foundation (Meridional Circulation and Heat Flux Array) and by the US National Oceanic and Atmospheric Administration (NOAA) Office of Climate Observations.

\footnotetext{
$1 \mathrm{~Sv} \equiv 1 \cdot 10^{6} \mathrm{~m}^{3} \mathrm{~s}^{-1}$ (unit for volumetric transport, named after Harald Ulrik Sverdrup)
} 
In this paper we will outline the observational strategy (section 2) and discuss a strategy for mitigation of risks involved in continuous ocean in situ measurements (section 3). We then present the MOC observations from the first deployment period and discuss them in the light of a simulation using a numerical model (section 4). This will be followed by a brief summary (section 5).

\section{Observational Strategy}

To monitor the MOC across a latitudinal band, the net meridional transport as a function of depth has to be captured continuously. ${ }^{23}$ At $26.5 \mathrm{~N}$, we find the following situation. The Gulf Stream flows northward through the roughly $800 \mathrm{~m}$ deep and $90 \mathrm{~km}$ wide Straits of Florida bounded by Florida and the Bahamas to the west and east (Fig. 1). The meridional flow through the $6000 \mathrm{~km}$ wide section between the Bahamas and the African coast, comprising both the upper ocean southward recirculation in the subtropical gyre and the deep southward export of NADW, can be subdivided into two physically fundamentally different components. First, the flow in a layer limited to the upper $60 \mathrm{~m}$ of the water column (called Ekman layer) is directly wind driven (it results from a balance between wind stress exerted on the sea surface and the Coriolis force). Second, the mid-ocean flow below the Ekman layer is in so called geostrophic balance, thus it is a result of a balance between the horizontal pressure gradient force and the Coriolis force. We require a total of five measurement systems to capture the three meridional flow components outlined above.

The Gulf Stream volume transport $T_{G S}$ has been monitored using a submarine cable nearly continuously since $1982 .{ }^{24}$ Charged particles (ions) carried by the Florida Current pass through the magnetic field of the Earth, inducing an electric field perpendicular to the motion of the ions. Variations in the $T_{G S}$ strength induce voltage variations $\Delta \Phi_{V}$ on a cable stretched across the Straits of Florida (parallel to the electric field), with a change in transport of $1 \mathrm{~Sv}$ corresponding to a 
voltage change of about 0.04 volts according to

(1) $T_{G S}=C_{0} \cdot \Delta \Phi_{V}$

with $C_{0}=24.42 \pm 0.56 \mathrm{~Sv} \mathrm{~V}^{-1}$ being a calibration constant inferred from direct estimates of $T_{G S} .^{25}$ The voltage variations are measured every second by a computerized voltage meter relative to an Earth ground, and the resulting voltage time series is low-pass filtered using a 72 hour cut-off period to remove ionospheric noise.

The meridional component of the Ekman transport in the thin Ekman layer zonally integrated between the Bahamas and the African coast is estimated according to

(2) $T_{E K}=-\int \tau_{x}(\rho f) d x$

where $\tau_{x}$ is the zonal component of the wind stress, and where $\rho$ and $f$ denote density and the Coriolis parameter, respectively. $\tau_{x}$ is estimated from the space borne Quickscat scatterometer measurements. ${ }^{26}$ They make use of an empirical relationship between wind speeds and the small (centimetre) scale roughness of the sea surface, with the latter being detectable from the power of backscattered microwave pulses. ${ }^{27}$ The wind stress data from Quickscat is available at a daily resolution.

In theory, the zonally integrated mid-ocean geostrophic transport $T_{M O}$ (per unit depth) at any depth level $z$ may be calculated from the horizontal difference in pressure $P$ between eastern and the western boundary (Africa and the Bahamas, respectively) according to ${ }^{28}$

(3) $T_{M O}(z)=\left[p_{E}(z)-p_{W}(z)\right] /[\rho f]$.

In practice, this is impossible, because neither are depth levels (or equigeopotential surfaces) known with sufficient precision nor can absolute pressures be measured directly with adequate accuracy. ${ }^{11}$ Therefore, we decompose $\mathrm{T}_{\mathrm{MO}}$ into three observable contributions. The geostrophic internal transport $\mathrm{T}_{\mathrm{INT}}$ can be measured from the density difference between the western and eastern 
boundary as

(4) $T_{I N T}(z)=-g /(f \rho) \int_{Z_{R E F}^{0}}^{0}\left[\rho_{E}\left(z^{\prime}\right)-\rho_{W}\left(z^{\prime}\right)\right] d z$

relative to the reference level $\mathrm{Z}_{\mathrm{REF}}\left(\mathrm{we}\right.$ use $\mathrm{Z}_{\mathrm{REF}}=-4740 \mathrm{~m}$ ) according to $^{28}$, with $\mathrm{g}$ denoting the gravitational constant. For this we compute density profiles at a daily resolution. At the western and eastern boundary densities derived from temperature $(\mathrm{T})$, conductivity $(\mathrm{C})$ and pressure measurements at discrete levels from three moorings (WB2, WBH1, WBH2) and six moorings (EB1, EBH1-5) have been used (Fig. 2). ${ }^{29}$

Zonal differences of ocean bottom pressure fluctuations $P_{B O T}$ (time mean has been removed) allow the computation of reference level meridional geostrophic velocity fluctuations. ${ }^{11}$ From these the vertically integrated northward external transport fluctuations $\overline{T_{E X T}^{i}}$ integrated between two stations $\mathrm{i}$ and $\mathrm{i}+1$ (counted from west to east) with water column height $H$ can be obtained as (5) $\overline{T_{E X T}^{i}}=H^{i} /(\rho f)\left[P_{B O T}^{i+1}-P_{B O T}^{i}\right]$.

$\overline{T_{E X T}^{i}}$ is computed between any pair of adjacent moorings (i.e., for WB1-WB2, WB2-WBH1, WBH1-WBH2,WBH2-EB1, ...). For the subsequent analysis the western to eastern boundary transport integral $T_{E X T}$ computed from the sum of the ten station pairs has been used (

$\left.T_{E X T}=\sum T_{E X T}^{i}\right)$

The fraction of the meridional transport over the continental slope west of WB1 (Fig.3, left) has been estimated by integrating velocities from direct current meter measurements at discrete levels on the moorings WBA, WB0, WB1..$^{30}$ Flows in this wedge are referred to as western boundary wedge transports ( $\left.T_{W B W}\right)$. T, C, P and current velocities are measured every 15 minutes. To eliminate tidal and inertial variability, the data are 2 day low-pass filtered and sub-sampled on a 
daily grid. The rationale for the vertical resolution of the T, C and P measurements (i.e. the vertical spacing of the sensors on the moorings) relies on simulations using historic hydrographic data ${ }^{31}$, while that of the current meters at the western boundary is based in experience gained in precursory experiments. $^{32}$

The fluctuating part of $\mathrm{T}_{\mathrm{MO}}(\mathrm{z})$ can approximated by the sum of the three components $\mathrm{T}_{\mathrm{INT}}(\mathrm{z})+$ $\mathrm{T}_{\mathrm{EXT}}(\mathrm{z})+\mathrm{T}_{\mathrm{WBw}}(\mathrm{z}) .^{28}$ An alternative way to derive absolute values of $\mathrm{T}_{\mathrm{MO}}(\mathrm{z})$ is to assume that there is not net (i.e. zonally and vertically integrated) mass transport across $26.5 \mathrm{~N}$, such that the vertical integral of $\mathrm{T}_{\mathrm{MO}}(\mathrm{z})$ balances the vertical integral of the sum of $\mathrm{T}_{\mathrm{EK}}(\mathrm{z})+\mathrm{T}_{\mathrm{GS}}(\mathrm{z}) .^{33}$ This procedure does not make use of $T_{E X T}$ but instead a barotropic transport profile is added to $T_{I N T}$ such, that zero net transport is obtained at each time step.

\section{Risk mitigation of the mooring array}

One aspect that has been central in the design of the RAPID-MOC system was the mitigation of risk arising from potential partial failures of its components. If for some reason the Quickscat wind measurements (used to determine $T_{E X T}$ ) failed, other wind field data of comparable quality would be available, such as the NCEP/NCAR re-analysis products. The cable measurements in the Straits of Florida have proven to work reliably over the past 25 years $^{24}$, however NOAA Atlantic Oceanographic and Meteorological Laboratory (Miami) is currently preparing to carry out voltage measurements on a second cable stretched across the Straits of Florida.

The entire mooring array (used to determine $T_{M O}$ ) is serviced roughly once every year involving two cruises - one covering the western boundary sub-array and the other covering the eastern boundary and Mid-Atlantic Ridge sub-arrays. ${ }^{34}$ The full array design deployed in 2004 is seen in Fig. 3. The implementation, maintenance and development of the array has been described. ${ }^{34}$ While deployed in 
the ocean for one-year-long periods, the moored observatories are exposed to various sources of risks. These involve destruction of moorings (or parts of moorings) by fishing vessels, material fatigue in strong ocean currents, corrosion and diverse sensor failure modes. Thus, a strategy had to be developed how risk in loosing data could be mitigated by backup and complementary measurement. In the following we highlight our strategy for the western boundary sub-array, which represents the most important element of the mooring array. Similar strategies exist for the other sub-arrays. One aspect of reducing risks of failures is choosing a conservative mooring design. There is positive net backup buoyancy at each depth level, and (for mooring extending into the top $200 \mathrm{~m}$ of the water column) the top part is staged, with the main buoyancy sphere (providing an uplift of typically $500 \mathrm{~kg}$ ) at around $200 \mathrm{~m}$ depth and smaller buoyancy spheres at 100 and $50 \mathrm{~m}$.

Compared to our other mooring sub-arrays, the western boundary sub-array is located where the largest transport and thus density (see eq. 4) fluctuations occur, related to the DWBC below $1000 \mathrm{~m}$ and the northward Antilles current above that level. ${ }^{30}$ If this sub-array failed to recover the vertical density structure at the western boundary, the time-variable MOC could not be determined reliably. The most critical density mooring is WB2, located right at the western boundary inshore of the DWBC, covering the depth range from $100-3800 \mathrm{~m}$. The depth range below $3800-4800 \mathrm{~m}$ is covered by the two smaller WBH1, WBH2 moorings, located just a few miles further offshore (Figs. 2 and 3).

A mooring complementary to the bulk of WB2, WBH1, WBH2 is WB3, which acquires density and direct current measurements, covering the $50-4800 \mathrm{~m}$ range (Fig. 3). It is located $14 \mathrm{~nm}^{\mathrm{B}}$ offshore of WB2, so that a non-negligible fraction of the DWBC passes between WB2 and WB3. ${ }^{30}$ If WB2 failed (which was partially the case from November 2005 to March 2006), the basin-wide integrated geostrophic flow could be determined by means of density measurements at WB3 and the eastern boundary, and the flow in the boundary triangle to the west could be determined by interpolating the current meter measurements between WB3 and WB1. In the 50 - 1400 m range WB1 (located 4

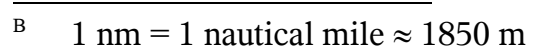


$\mathrm{nm}$ to the west and upslope of WB2) can serve as a backup.

In the April 2004 - April 2005 deployment period we used the western boundary bottom pressure recorders (BPR) from WB1, WB2, WBH1, WBH2 to compute $\mathrm{T}_{\mathrm{EXT}}$. If any of those had failed, direct current meter measurements at WB1, WB2 and WB3 (as meridional transports correspond to zonal gradients in pressure - see eq. 3) and the bottom pressure measurements at WB3 could have been used to fill the gap. From 2005 onwards our BPR measurement scheme has changed substantially throughout the whole array. It was decided to deploy BPRs at key sites only, both to increase data quality and to mitigate risks. Therefore the sensors have been mounted on "landers" separately from the density moorings since then. This allows for 2-year-long deployment durations which is critical for recovering low-frequency (inter-annual) variability. ${ }^{35}$ At the western boundary bottom pressure measurements are now only carried out at WB2, WB3. The lander at WB2 (key site) is equipped with two sensors to allow for backup. Further contingency and better recovery of low-frequency variability is achieved by the temporal overlapping scheme now maintained at all BPR sites. That means, in the first year a lander is deployed, and in the second year another lander is deployed at the same site. From the third year onwards, the lander whose mission reaches 2 years is recovered and redeployed. This ensures (i) temporal overlap of one year between the two landers, (ii) two-year-long records and (iii) annual retrieval of data. By this means we will match BPR records from each time series using the annual overlap to obtain uninterrupted multi-year time series of bottom pressure fluctuations. ${ }^{35}$

The current meter measurements in the western boundary wedge (west of the geostrophic array) provide $\mathrm{T}_{\mathrm{WBW}}$ and are for the calculation of the MOC profile. ${ }^{30}$ Current measurements are carried out on WBA (equipped with an ADCP deployed at 400 m water depth), WB0, WB1, WB2 and WB3 (Fig 3). WB0 can serve as a backup mooring for WB1, being just $2 \mathrm{~nm}$ upslope (west) of it. 
The vulnerability of the current meter array in the western boundary wedge was tested by recalculating transports when omitting data from one or more moorings. When omitting one of the WBA, WB0, WB1 moorings the rms transport difference does not exceed $0.5 \mathrm{~Sv}$; when omitting any two of the moorings the differences stays below 1.0 Sv. These values are acceptable and show that the western boundary wedge is neither over- nor under-sampled.

\section{First results}

We now report on the main scientific findings from April 2004 to April 2005 observational period. The five different transport contributions (integrated over the whole water column) are shown in Fig. 4. With the RAPID / MOCHA experiment essentially being a pilot study, observational evidence for the validity of the MOC monitoring approach was lacking. The MOC is widely regarded to consist of a near-surface northward flow of warm water compensated by a cold southward return flow at depth. As a consequence of the compensation, the net (top to bottom integrated) meridional flow across $26.5 \mathrm{~N}$ should be small, though non-zero due to the inflow of $0.83 \pm 0.66 \mathrm{~Sv}$ from the Pacific through Bering Strait. ${ }^{36}$ Thus, one can assume that the five different transport components we observe (Fig. 4 a) compensate for each other, such that overall mass balance is achieved. We have been able to show for the first time that this mass balance exists at periods longer than ten days (Fig. $4 \mathrm{~b})^{28}$, with the sum of $T_{G S}+T_{E K}$ fluctuating in anti-phase with $T_{M O}$, and interpret this as a strong indication that the monitoring approach taken is valid and that the RAPID / MOCHA system is working reliably. Interestingly, in contrast to a long standing paradigm, the density-inferred transport fluctuations $T_{I N T}$ show strong fluctuations on periods shorter than a month (Fig. 4 a).

Based on the above transport observations, a continuous time series of the strength of the MOC has been derived by Cunningham et al. (2007), defined as the maximum northward upper ocean transport on each day (Fig. 5). The flow is found to be northward between the sea surface and 
roughly the $1100 \mathrm{~m}$ depth level - as a consequence of the northward flow of the Gulf Stream, the Antilles Current and the Ekman flow - and is compensated by a southward flow below that, concentrated mostly within the $\mathrm{DWBC}^{30}$. At $26.5 \mathrm{~N}$ the strength of the MOC shown in Fig. 5 has a mean of $18.7 \mathrm{~Sv}$ and varies by $\pm 5.6 \mathrm{~Sv}$ (one standard deviation) over the one year period of observations $^{33}$, occupying a range of values between 4 and $35 \mathrm{~Sv}$. The MOC time series displays drastic changes in its strength not only on a seasonal time scale but at periods as short as weeks to months.

The first year of observations shows that the variability of the MOC shown in Fig. 5 is shared almost evenly between contributions from $\mathrm{T}_{\mathrm{EK}}$ and from density driven transports (to which $T_{I N T}$, $T_{G S}$ and $T_{W B W}$ contribute). Sub-annual fluctuations of the Ekman transport can readily be understood based on Ekman theory. However, the mechanisms behind the rapid fluctuations found in the density field at the ocean margins are not fully understood yet. The data from the RAPID-MOCHA monitoring array originates from few locations found mainly at the margins. Based on these observations not much can be said about the zonal structure of the meridional flow linked to the boundary densities. Numerical models allow highlighting possible variability mechanisms, as they can be used to put the local information from the ocean margins at $26.5 \mathrm{~N}$ into a wider spatial context. We used the Atlantic domain of a $1 / 4^{\circ}$ version of OCCAM (Ocean Circulation and Climate Advanced Modelling Project) described $\mathrm{in}^{37,38,39}$, to investigate the MOC variability. ${ }^{14}$ The model is forced at the surface with realistic winds, heat fluxes and salinities. It simulates the global ocean circulation for the years 1985 to 2003. As in the observations, the MOC at $26.5 \mathrm{~N}$ simulated in the numerical model exhibits a large variability - even on sub-annual time scales (Figure 6a). An MOC estimate calculated using the same approach as for the observations illustrates that there is good agreement between the MOC and its reconstruction (Fig. 6a). As in the observations sub-annual variability in the transport is found both in $T_{E K}$ and $T_{I N T}$ (Fig. 6b,c). The fluctuations in $T_{I N T}$ can be put into a wider spatial context by looking at the zonal structure of transport anomalies (Fig. 6d). Anomalies of $T_{I N T}$ are 
illustrated for $1100 \mathrm{~m}$ depth with the cumulative (zonal) internal transport

(6) $T_{I N T_{C}}(x, z)=\int_{-1100}^{0} d z \int_{x_{E}}^{x} v^{\prime} d x$

where $v^{\prime}$ is the velocity obtained from zonal density differences, $x_{E}$ denotes the location of the eastern margin, and $z$ is the vertical coordinate.

The variability is not confined to the boundaries but occurs across most of the basin width (Fig. 6d). The amplitude of the transport fluctuations reaches its largest values in the western half of the basin. An interesting feature emerging from Fig. $6 \mathrm{~d}$ is the indication of a westward propagation of transport anomalies. Certain anomalies can be "tracked" over several years while others are shortlived. The signals always tend to propagate westward with the same velocity and a signal typically takes about 5 years to cross the basin which is equivalent to a propagation velocity of $4 \mathrm{~cm} / \mathrm{s}$. Such propagation speeds are consistent with the propagation of long internal Rossby waves at the latitude of $26.5 \mathrm{~N} .{ }^{28}$ Internal Rossby waves occur as a consequence of vertical displacements of isopycnals (surfaces of constant potential sea water density). The westward propagation of long waves is a consequence of the latitudinal dependence of the Coriolis parameter. ${ }^{28}$ The main message from the model results summarised in Fig. 6 is that the variability of the MOC/internal transport cannot just be understood as a western boundary process. Even if the anomalies that ultimately matter for the basin-wide transport (and thus for the MOC) are those found at the ocean margins, the origin of some of the anomalies may be found in the basin interior from where the perturbations propagate towards the western boundary as internal waves.

\section{Discussion and Summary}

The basic strategy that has been chosen to obtain continuous observations of the strength and vertical structure of the MOC in this pilot experiment is simple and cost-efficient. It makes use of zonally integrating measurement techniques, such as voltage variations in the Straits of Florida and 
density and bottom pressure on either margin of the Atlantic. Additionally, the wind-stress data from remote sensing conveniently allow us to integrate transport vertically over the near-surface Ekman layer.

We have presented a strategy to ensure that the monitoring system, which relies on five well-tested measurement components, should be robust against partial failures of the components. For the mooring components - which are serviced annually - this is ensured by a strategy of backup and complementary measurements, and a temporal overlap deployment scheme (for BPRs). A further large step forward to reduce risks of loosing data due to failures, and to diagnose potential data problems early, would be a data telemetry system at each (principal) mooring site that communicates the data via satellite directly to the laboratory at regular intervals. We made tests with a system that relied on a telemetry buoy (attached with a cable to the main mooring) which was supposed to reside at the sea surface throughout the deployment. In all trials, however, the surface buoy got mechanically detached from the mooring within a few weeks time. Other solutions, such as bottom mounted systems, will need to be tested.

Given that the different transport component compensate for each other on periods longer than 10 days, we have presented strong observational evidence that the system is detecting the strength of the MOC reliably, with the mid-ocean transport varying in anti-phase with the sum of Ekman and Gulf Stream transports. The April 2004 to April 2005 average MOC strength is 18.7 Sv and it varies by $\pm 5.6 \mathrm{~Sv}$ (one standard deviation) with a maximum value of 35 and a minimum of $4 \mathrm{~Sv}$. The observed rapid intra-seasonal variability raises concerns whether the alarming $30 \%$ decline in the MOC inferred from only 5 snapshot measurements over the last 50 years ${ }^{10}$ is due to aliasing effects (resulting from not adequately resolving the temporal variability) rather than a sustained change in the ocean circulation. To infer climate change induced trends in the MOC, continuous observations such as from RAPID-MOC over several decades may have to be required ${ }^{40}$. 
In contrast to a long standing paradigm, we find surprisingly large fluctuations in the density-driven transports on intra-seasonal time scales (longer than 20 days). This is confirmed by findings from a general ocean circulation model. The simulation implies that parts of the density fluctuation observed at the ocean boundaries may actually originate from internal Rossby waves that propagate westward.

\section{Acknowledgements}

The authors would like to thank the captains and crews of the research vessels Charles Darwin, Discovery, Ronald Brown and Knorr and the UKORS mooring team. The mooring operations have been funded NERC RAPID and NSF. The Florida Current cable data are made freely available by the Atlantic Oceanographic and Meteorological Laboratory (www.aoml.noaa.gov/phod/floridacurrent/) and are funded by the NOAA Office of Climate Observations. The wind stress data were obtained from CERSAT, at IFREMER, Plouzané (France).

References

(1) Dicksen R. and Brown, J., 1994. Journal of Geophysical Research, 99, 12319

(2) Fine, R. N. and R. L. Molinari, 1988: A continuous deep western boundary current between Abaco $\left(26.5^{\circ} \mathrm{N}\right)$ and Barbados $\left(13^{\circ} \mathrm{N}\right)$. Deep Sea Research I, 35, 1441-1450.

(3) Bryden, H. L., and S. Imawaki. 2001. Ocean heat transport, in Ocean Circulation and Climate, edited by G. Siedler, J. Church and J. Gould, Academic Press, 455-474.

(4) Rahmstorf, S., 2003. Nature, 421, 699

(5) Dansgaard, W., and 10 others. 1993. Evidence for general instability of past climate from a 250-kyr ice-core record, Nature, 364, 218-220.

(6) Vellinga, M., and R. A. Wood. 2002. Global climatic impacts of a collapse of the Atlantic 
thermohaline circulation, Climatic Change, 54, 251-267.

(7) Gregory, J. M., and 17 others. 2005. A model intercomparison of changes in the Atlantic thermohaline circulation in response to increasing atmospheric $\mathrm{CO} 2$ concentration, Geophysical Research Letters, 32, L12703, doi:10.1029/2005GL023209.

(8) Koltermann, T., A. V. Sokov, V. P. Tereschenkov, S. A. Dobroliubov, K. Lorbacher, and A. Sy, 1999: Decadal changes in the thermohaline circulation of the North Atlantic. Deep Sea Research Part II, 46, 109-138.

(9) Ganachaud, A., and C. Wunsch. 2002.Large-scale ocean heat and freshwater transports during the World Ocean Circulation Experiment, Journal of Climate, 16, 696-705.

(10) Bryden, H. L., H. L. Longworth, and S. A. Cunningham. 2005. Slowing of the Atlantic Meridional Overturning Circulation at $25^{\circ} \mathrm{N}$, Nature, 438, 655-657.

(11) Whitworth, T., 1983: Monitoring the transport of the Antarctic circumpolar current at Drake Passage. Journal of Physical Oceanography, 13, 2045-2057.

(12) Larsen, J. and T. B. Sanford, 1985. Science, 227, 302

(13) Willebrand, J., S. G. H. Philander, and R. C. Pacanowski, 1980: The oceanic response to large-scale atmospheric disturbances. Journal of Physical Oceanography, 10, 411-429. (14) Hirschi J., Killworth P.D., Blundell J.R., 2007: Subannual, seasonal and interannual variability of the North Atlantic meridional overturning circulation.

Journal of Physical Oceanography, 37, 1246 - 1265

(15) Jayne, S. and J. Marotzke, 2001. Reviews of Geophysics, 39, 385

(16) Dong, B.-W. and R. T. Sutton, 2001: The dominant mechanisms of variability in the Atlantic Ocean heat transport in a coupled ocean-atmosphere GCM. Geophysical Research Letters, 28, 2445-2448.

(17) Lherminier, P., H. Mercier, C. Gourcuff, M. Alvarez, S. Bacon, and C. Kermabon (2007), Transports across the 2002 Greenland-Portugal Ovide section and comparison with 1997, $J$. Geophys. Res., 112, C07003, doi:10.1029/2006JC003716. 
(18) Hansen, B., W. R. Turrell and S. Østerhus. 2001. Decreasing outflow from the Nordic seas into the Atlantic Ocean through the Faroe Bank channel since 1950, Nature, 411, 927-930. (19) Dengler, M., J. Fischer, F. A. Schott, and R. Zantopp (2006), Deep Labrador Current and its variability in 1996-2005, Geophys. Res. Lett., 33, L21S06, doi:10.1029/2006GL026702. (20) Schott, F. A., J. Fischer, M. Dengler, and R. Zantopp (2006), Variability of the Deep Western Boundary Current east of the Grand Banks, Geophys. Res. Lett., 33, L21S07, doi:10.1029/2006GL026563.

(21) Lee, T.N., W.E. Johns, R. Zantopp, and E.R. Fillenbaum, 1996: Moored observations of western boundary current variability and thermohaline circulation $26.5^{\circ} \mathrm{N}$ in the subtropical North Atlantic, Journal of Physical Oceanography, 26, 962-963.

(22) Kanzow, T., 2004: Monitoring the integrated deep meridional flow in the tropical North Atlantic. Dissertation. Christian-Albrechts-Universität Kiel.

(23) Hirschi, J., J. Baehr, and J. Marotzke, J. Stark, S. Cunningham, J.O. Beismann, 2003: A monitoring design for the Atlantic meridional overturning circulation. Geophysical Research Letters, 30.

(24) Baringer, M. O., J.C. Larsen. 2001. Sixteen years of Florida Current transport at $27^{\circ}$ N. Geophys. Res. Lett., 28, 3197-3182.

(25) Larsen, J.C.,1992: Transport and heat flux of the Florida Current at $27^{\circ} \mathrm{N}$ derived from cross-stream voltages and profiling data: theory and observations. Philosophical Transactions of the Royal Society of London A, 338, 169-236.

(26) Graf, J., C. Sasaki, C. Winn, T. Liu, W. Tsai, M. Freilich, and D. Long, (1998): NASA scatterometer experiment. Acta Astronautica 43, 397-407

(27) Jones, W.L, F. J. Wentz and L.C. Schroeder, 1978. Algorithm for inferring wind stress from SEASAT-A. Spacecraft and Rockets, 15, 368-374

(28) Apel, J.R., 1988. Principles of Ocean Physics. International Geophysics Series, 38, 
Academic Press

(29) Kanzow, T., S. A. Cunningham, D. Rayner, J. J.-M. Hirschi, W. E. Johns, M. O. Baringer, H. L. Bryden, L. M. Beal, C. S. Meinen, and J. Marotzke, 2007: Flow compensation associated with the MOC at $26.5^{\circ} \mathrm{N}$ in the Atlantic. Science, 317, 938-941.

(30) Johns, W. E., L. M. Beal, M. O. Baringer, J. Molina, D. Rayner, S. A. Cunningham, and T. Kanzow, 2007: Variability of shallow and deep western boundary currents off the Bahamas during 2004-2005: First results from the $26^{\circ} \mathrm{N}$ RAPID-MOC array. J. Phys. Oceanog., in press.

(31) Kanzow , T., 2000. Integrale Erfassung langperiodischer Transporte: Simulation und Optimierung eines verankerten Systems - Diploma Thesis. Institut für Meereskunde, Kiel.

(32) Johns, W. E., T. Kanzow, and R. Zantopp, 2005: Estimating ocean transports with dynamic height moorings: An application in the Atlantic deep western boundary current. Deep-Sea Research I, 52, 1542-1567.

(33) Cunningham, S. A., T. O. Kanzow, D. Rayner, M. O. Barringer, W. E. Johns, J. Marotzke, H. R. Longworth, E. M. Grant, J. J.-M. Hirschi, L. M. Beal, C. S. Meinen, and H. L. Bryden, 2007: Temporal variability of the Atlantic Meridional Overturning Circulation at $26.5^{\circ} \mathrm{N}$. Science, 317, 935-938.

(34) Rayner, D., 2007. Monitoring the Atlantic Meridiional Overturning Circulation. IEEE Sytems Journal (Special Issue on "Creating a Global Earth Observation System of Systems”), submitted

(35) Kanzow, T., Send, U., Zenk, W., Chave, A.D., Rhein, M., 2006: Monitoring the integrated deep meridional flow in the tropical North Atlantic: Lon-term performance of a geostrophic array. Deep-Sea Research I, 53, 528-546

(36) Roach, A. T., K. Aagaard, C. H. Pease, S. A. Salo, T. Weingartner, V. Pavlov, and M. Kulakov (1995): Direct measurements of transport and water properties through the Bering 
Strait, J. Geophys. Res., 100, 18,443-18,458

(37) Webb, D. J., 1996. An ocean model code for array processor computers. Computational Geosciences, 22, 569-578

(38) Marsh, R., B. A. de Cuevas, A. C. Coward, H. L. Bryden and M. Álvarez, 2005. Thermohaline circulation at three key sections in the North Atlantic ober 1985-2002. Geophysical Research Letters, 32, doi: 10.1029/2004GL022281

(39) Marsh, R., B. A. de Cuevas, A. C. Coward, J. G. Nurser and S. A. Josey, 2005. Water mass tranformation in the North Atlantic over 1985 - 2002 simulated in an eddy-permitting model. Ocean Science Discussions, 1, 127-144

(40) Baehr, J., Haak, H., Alderson, S., Cuningham, S.A., Jungclaus, J.H., Marotzke, J. (2007): Timely detection of changes in the meridional overturning circulation at $26^{\circ} \mathrm{N}$. Submitted to Journal of Climate

(41) Cunningham, S. A., 2005a: RRS Discovery Cruises 277 (26 MAR - 16 APR 2004) and 278 (19 MAR - 30 MAR 2004): Monitoring the Atlantic Meridional Overturning Circulation at $26.5^{\circ} \mathrm{N}$. Cruise Report 53, $150 \mathrm{pp}$.

(42) Cunningham, S. A., 2005b: RRS Discovery Cruise 279, 04 APR - 10 MAY 2004: A transatlantic hydrographic section at $24.5^{\circ}$ N. Cruise Report No. $54,150 \mathrm{pp}$.

(43) Church, J., 2007: Oceans: A change in circulation? Science, 317. 908 - 909, doi: 10.1126/science. 1147796

\section{FIGURES}



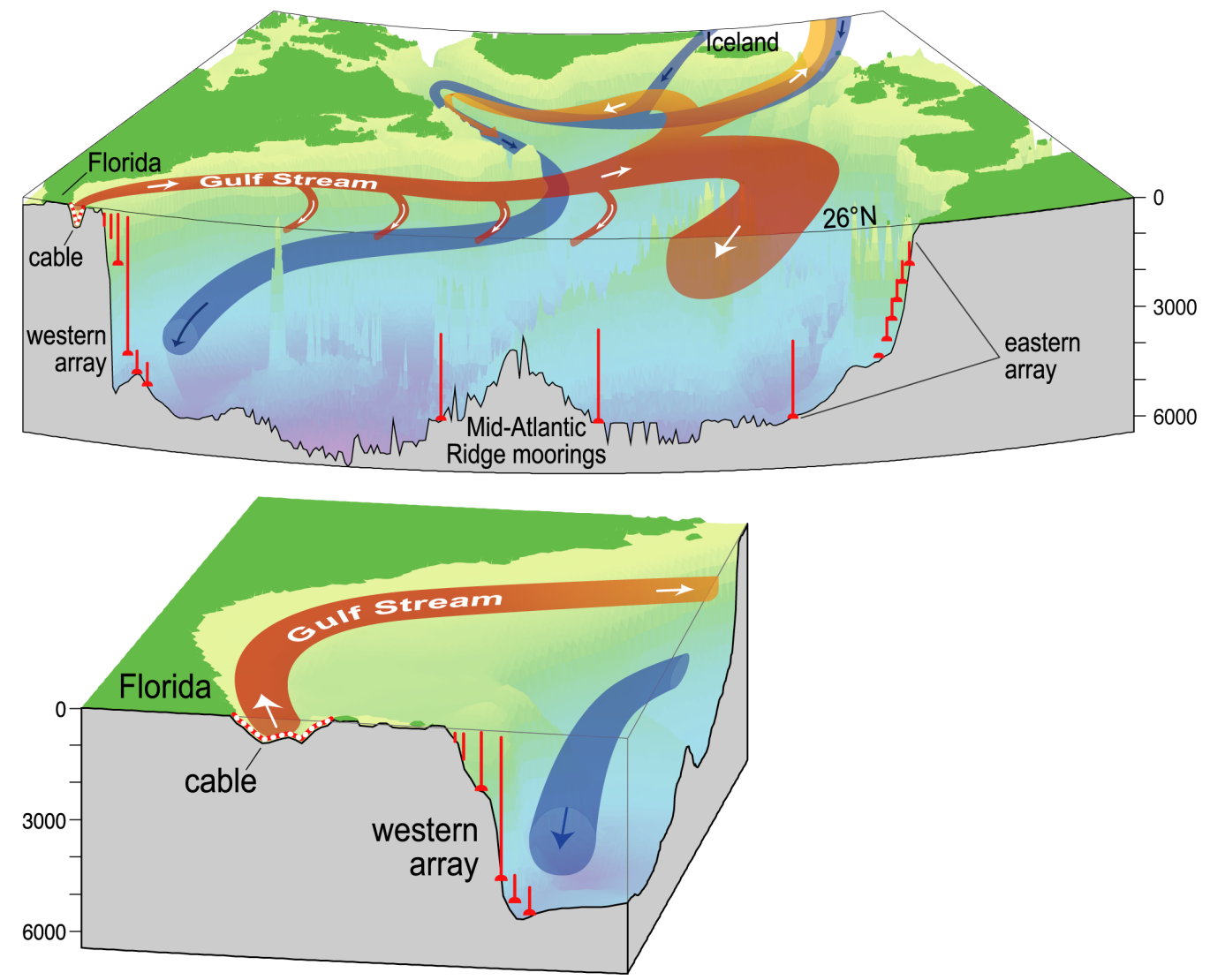

Louise Bell/Neil White, CSIRO

Figure 1

Upper panel: Schematics of the oceanic flow in the North Atlantic north of $26.5 \mathrm{~N}$ (from Church, 
$2007^{43}$, prepared by L. Bell and N. White, CSIRO). The upper and deep branches of the flow are indicated by red and blue colouring, respectively. Also included are the RAPID / MOCHA moorings at the western and eastern boundary of the North Atlantic and on both flanks of the MidAtlantic Ridge and the NOAA/AOML Florida current cable-based monitoring system.

The lower panel allows an expanded view on Straits of Florida and western boundary part of the MOC monitoring system.

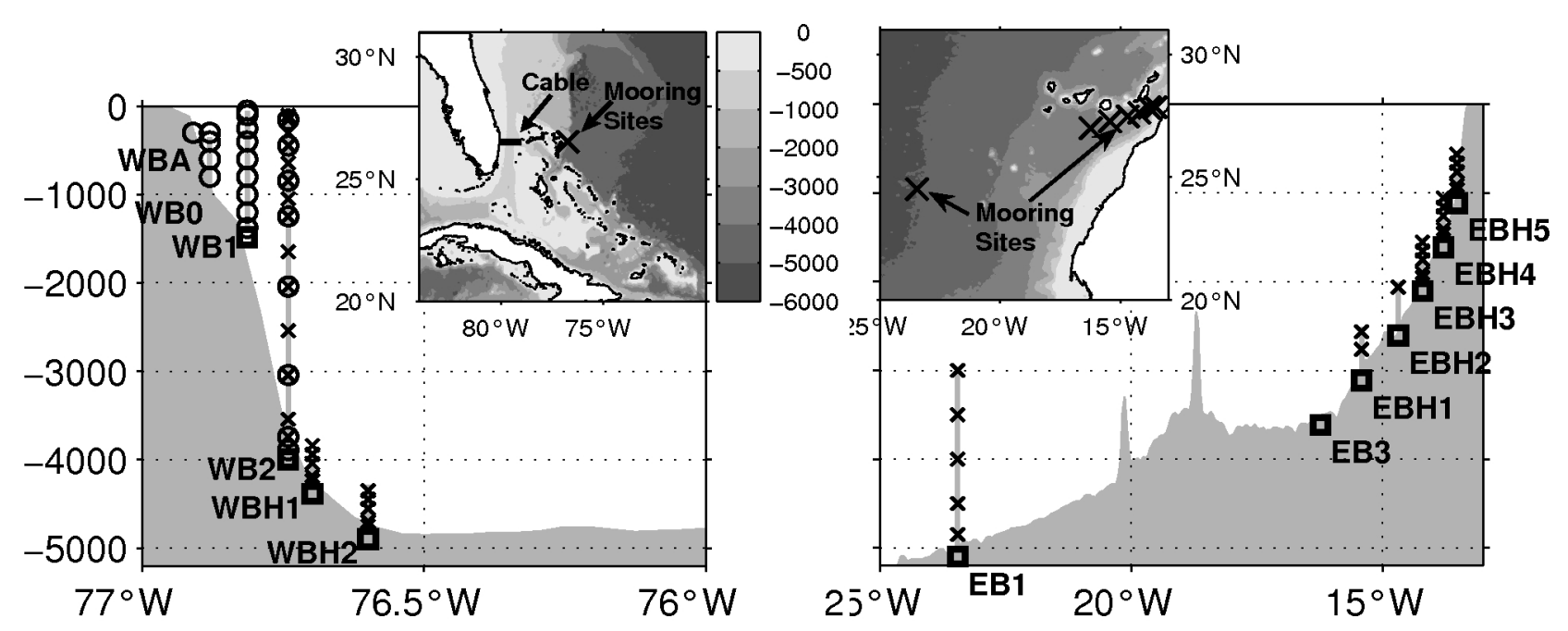

Fig. 2: Distribution of density (crosses) and bottom pressure sensors (squares) of the RAPID-MOC moorings at the western and eastern boundaries of the Subtropical North Atlantic near $26.5^{\circ} \mathrm{N}$ that are used for computing the zonally integrated meridional geostrophic flow (from Kanzow et al., 2007). ${ }^{29}$ Direct current meter measurements at the western boundary (circles) complement the observations in the upper part of the western boundary continental slope. The location of the western and eastern boundary mooring sites and of the Straits of Florida telephone cable can be seen in the small insets. 

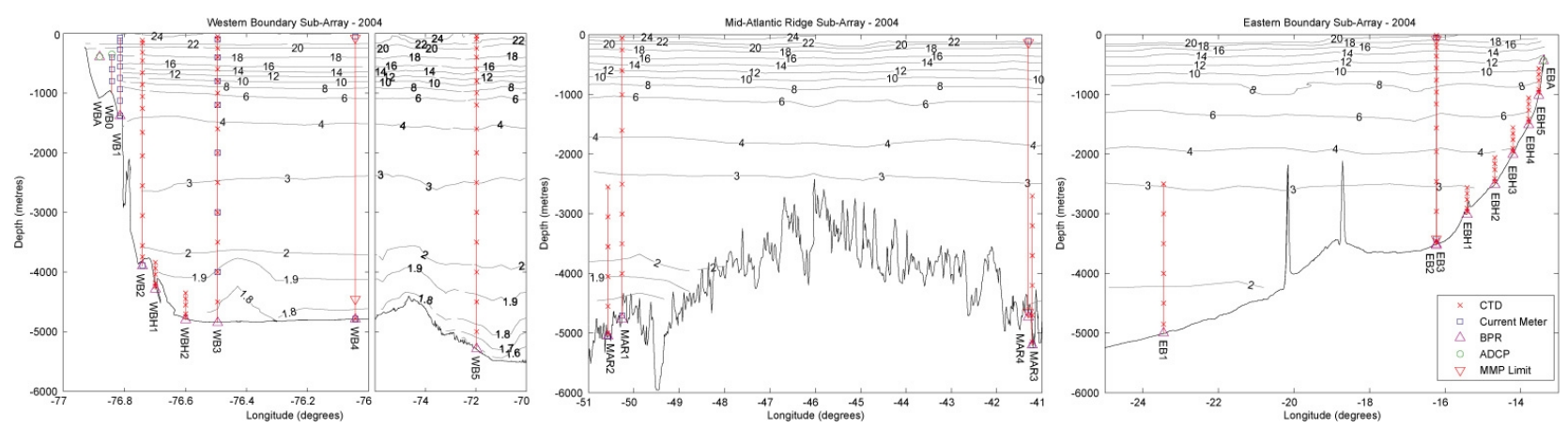

Fig. 3: Schematic of the three RAPID mooring sub-arrays as deployed in March and April 2004 (Cunningham, S. A., 2005a). ${ }^{34}$ Moorings are the vertical red lines and instruments symbols are defined in the key on the right hand panel (CTD - Conductivity, Temperature, Depth recorder, Current Meter - direct velocity measuring instrument, BPR - bottom pressure recorder measuring the hydrostatic weight of water, $\mathrm{ADCP}$ - an acoustic Doppler current profiler and MMP limit is the range profiling range of a profiling self propelled CTD). Distribution of potential temperature was obtained on a transatlantic hydrographic transect in 2004 following the deployment of the mooring arrays (Cunningham, S.A., 2005b) 

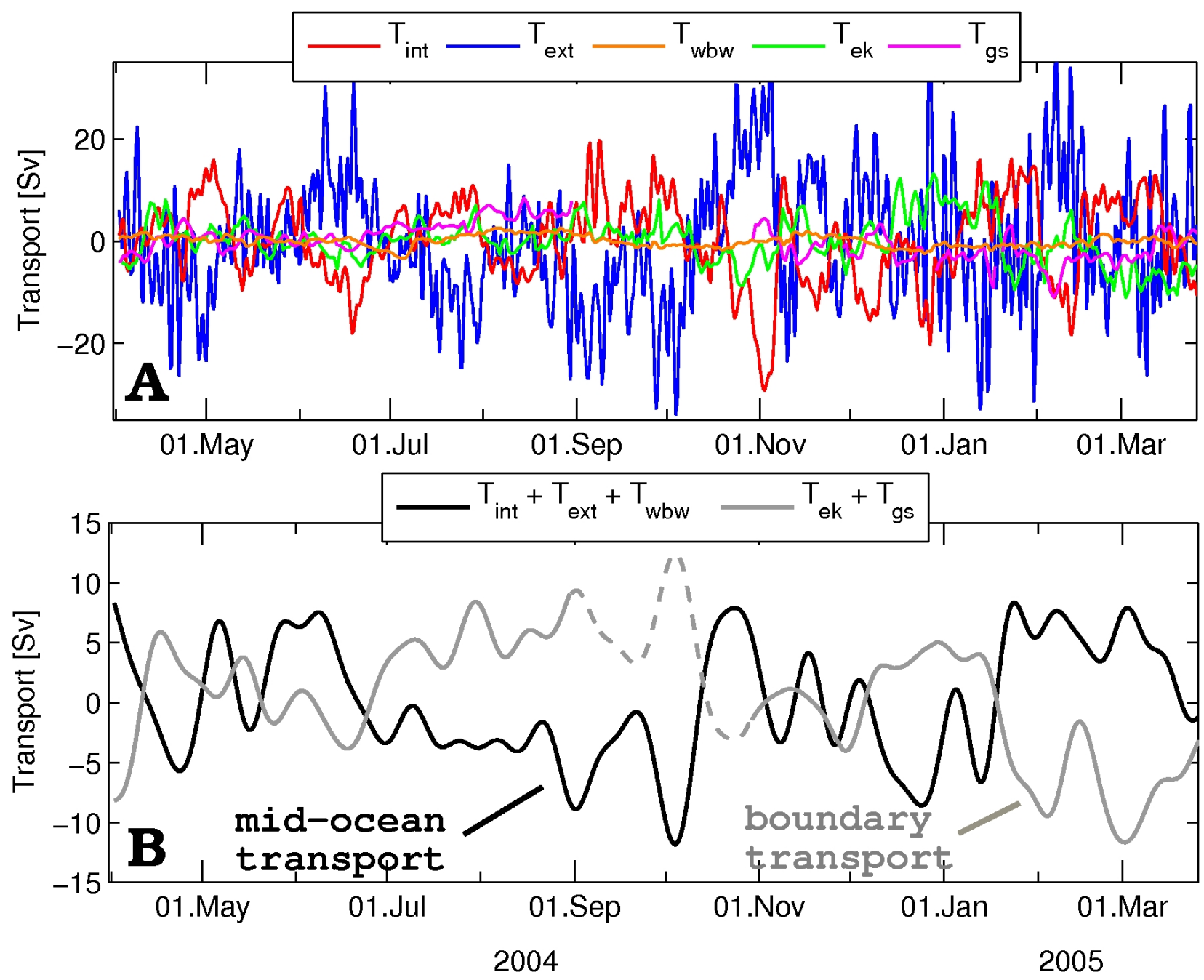

Fig. 4: (A) Fluctuations of the five observed transport components from which the MOC strength has been derived: mid-ocean internal $\left(\mathrm{T}_{\mathrm{INT}}\right.$, red) external $\left(\mathrm{T}_{\mathrm{EXT}}\right.$, blue), western boundary wedge ( $\mathrm{T}_{\mathrm{WBW}}$, orange) transports. ${ }^{29}$ The near surface Ekman transport ( $\mathrm{T}_{\mathrm{EK}}$, green) and transport of Gulf Stream $\left(\mathrm{T}_{\mathrm{GS}}\right.$, magenta) through the Straits of Florida are shown, too. There is a 2-month gap in $\mathrm{T}_{\mathrm{GS}}$ between 31 August and 29 September 2004. All time series were 
2-day low-pass filtered and sub-sampled on a half-daily grid. The initial sampling rates were 15 minutes for the underlying density and current measurements and 10 minutes for the bottom pressure. (B) Fifteen-day low-pass-filtered fluctuations of vertically integrated mid-ocean $\left(\mathrm{T}_{\mathrm{MO}}=\right.$ $\left.\mathrm{T}_{\mathrm{INT}}+\mathrm{T}_{\mathrm{EXT}}+\mathrm{T}_{\mathrm{WBW}}\right)$ and boundary transports $\left(\mathrm{T}_{\mathrm{BOUND}}=\mathrm{T}_{\mathrm{EK}}+\mathrm{T}_{\mathrm{GS}}\right)$ as black and gray lines, respectively. The dashed part of the gray line denotes the period when $\mathrm{T}_{\mathrm{GS}}$ could not be measured. A linear regression between $\mathrm{T}_{\mathrm{MO}}$ and $\mathrm{T}_{\mathrm{BOUND}}$ was used to fill this gap.

\section{Atlantic Meridional Overturning Circulation at $26.5^{\circ} \mathrm{N}$}

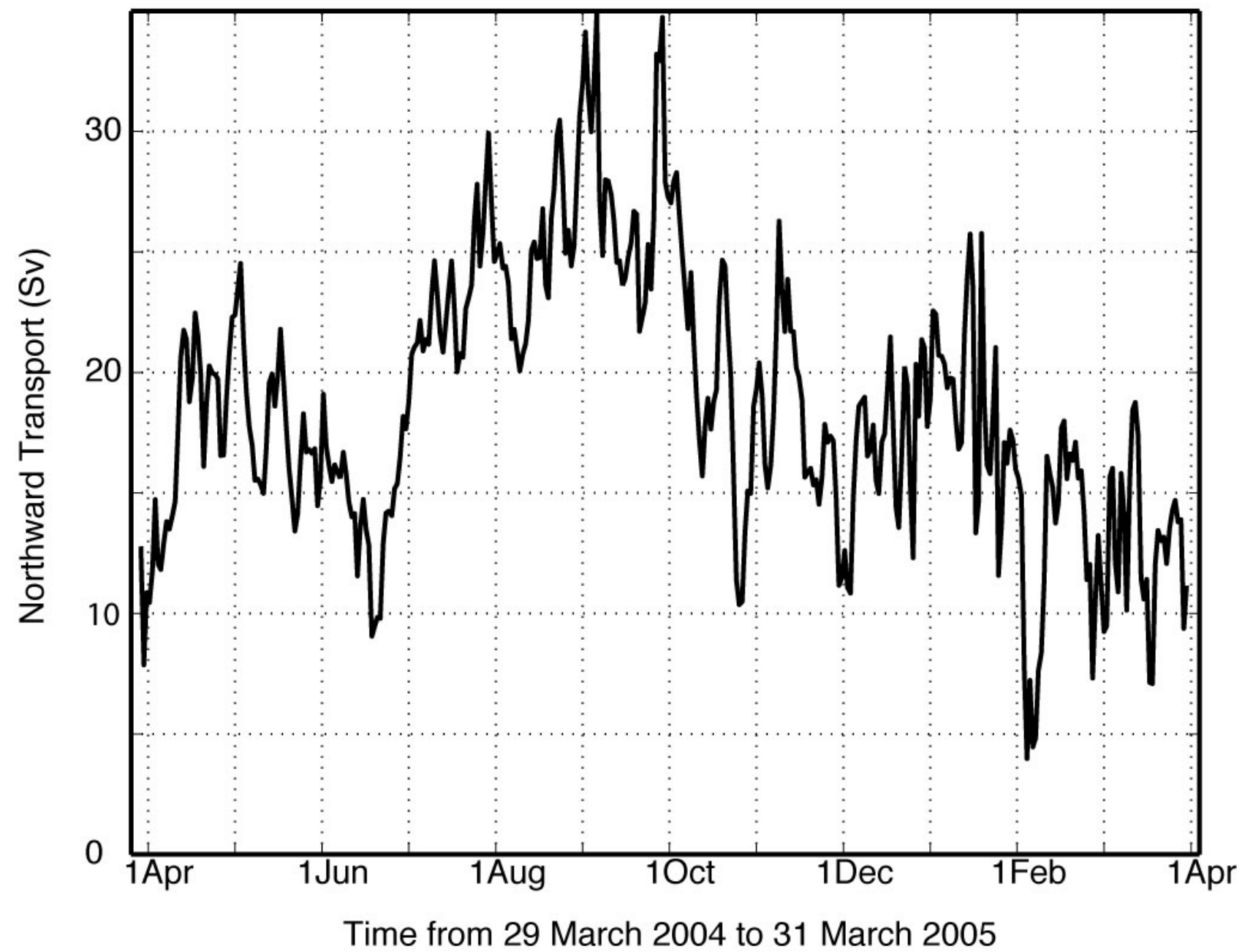

Fig. 5: Time series of the strength of the meridional overturning, based on the RAPID / MOCHA time series, is the vertical integral of the transport per unit depth down to the deepest northward velocity $(\sim 1100 \mathrm{~m})$ on each day. ${ }^{33}$ It represents the sum of the Florida Straits, Ekman, and upper mid-ocean transports. 

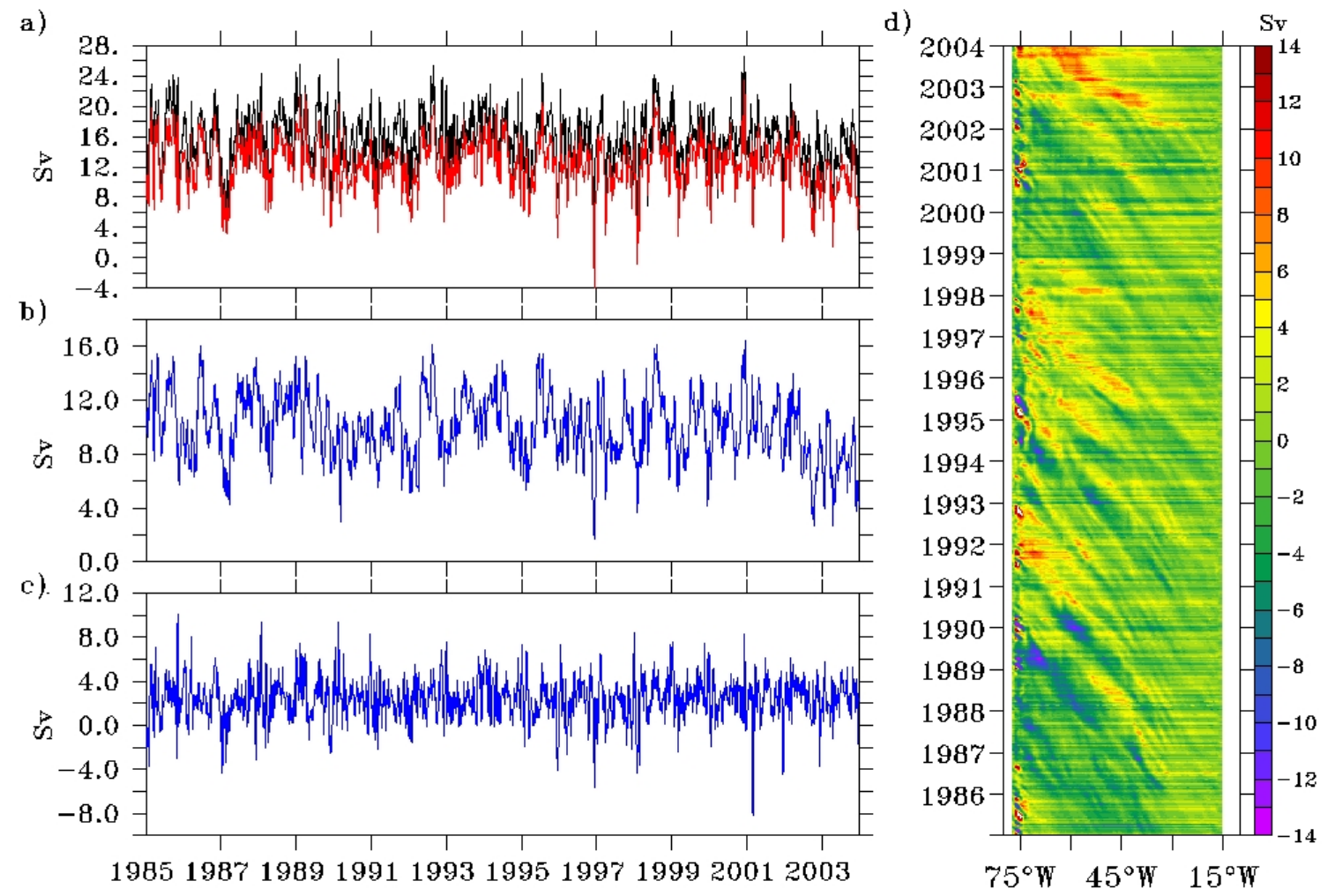

Figure 6: Variability of the MOC at $26.5 \mathrm{~N}$ in a numerical model (OCCAM). (a) MOC (black) and reconstruction (red) at 1100m depth (b) Sum of internal and Florida Straits transports (c) Ekman transport (d) zonal structure of cumulative internal transport (eq. 6) anomalies at 1100m depth. 